RUNNING HEADLINE: Maternal verbal interactive style

\title{
MATERNAL VERBAL RESPONSIVENESS AND DIRECTIVENESS: CONSISTENCY, STABILITY AND RELATIONS TO CHILD EARLY LINGUISTIC DEVELOPMENT
}

${ }^{1}$ Leila Paavola-Ruotsalainen, ${ }^{2}$ Jaana Lehtosaari, ${ }^{3}$ Josefina Palomäki and ${ }^{4}$ Immi Tervo

${ }^{1}$ University of Oulu, Faculty of Humanities, Logopedics, Child Language Research Center, Oulu, Finland

${ }^{2}$ Coronaria Kuntoutus Oy Ltd, Therapy Center, Oulu, Finland

${ }^{3}$ Coronaria Kuntoutus Oy Ltd, Therapy Center, Helsinki, Finland

${ }^{4}$ CogniMed Oy Ltd, Therapy Center, Helsinki, Finland 


\begin{abstract}
Maternal responsive and directive speech to children at $0 ; 10$ and 2;0 was investigated by applying a procedure first introduced by Flynn and Masur (2007) to a new language community (Finnish). The issues examined were consistency and stability over time and also the role of responsiveness and directiveness in child linguistic development at 1;0 and $2 ; 6$. The measures of maternal speech from each age were used to predict the results of the subsequent linguistic assessment. Negative correlations between responsive and directive utterances were found at both ages. The frequencies of responsive utterances and supportive directives increased over time. Responsiveness was positively and intrusive directiveness negatively related to child early comprehensive skills and the use of symbolic actions and communicative gestures. By contrast, no relations were found between responsiveness and directiveness and children's later linguistic capacities.
\end{abstract}




\section{INTRODUCTION}

Language acquisition is influenced by various genetic and biological factors, and also by social environmental factors (Harrison \& McLeod, 2010). It is important to acknowledge an interaction between different factors as well as their joint effects (Desmarais, Sylvestre, Meyer, Bairati \& Rouleau, 2008). Although humans are claimed to have an innate, genetically determined predisposition towards language acquisition and processing, early language experiences are needed to activate genetic programmes underlying language production and comprehension (Arshavsky, 2009). For example, Bruner $(1981,1983)$ has pointed out that in this learning process, early routinized social activity, where the mother or other caretaker interprets the child's signals and imputes meanings to them, as well as the caretaker's ability to follow the child's attentional focus are of key importance. In fact, a considerable number of studies of maternal verbal interactive style, or child-directed speech (CDS), have concluded that it plays an important role in the development of children's early communicative and linguistic skills (e.g. Masur, Flynn \& Eichorst, 2005; Tamis-LeMonda, Bornstein \& Baumwell, 2001). CDS is referred to as a particular manner of speaking and it is characterized by simplified syntax and meaning, and exaggerated prosodic structure as if adapted to the capacities of the child (e.g. Ferguson, 1978/2004). Additional studies are still needed in order to generate more accurate and profound conclusions about the role of maternal interactive style in child early language acquisition. This line of research is important, not least because it is closely related to speech and language therapy, in particular to interactive models of language intervention (e.g. Ciccone, Hennessey \& Stokes, 2012; Gibbard, Coglan \& MacDonald, 2004; Girolametto, Weitzman, Wiigs \& Pearce, 1999; Kaiser \& Hancock, 2003; Roberts \& Kaiser, 2011). 
The reports of the earlier studies of the possible language-facilitating characteristics of CDS have emphasized, for example, the importance of fine-tuning the structural and conceptual complexity of verbal communication to the child's developmental level (Bornstein, Tamis-LeMonda \& Haynes, 1999; Furrow, Nelson \& Benedict, 1979; Landry, Smith \& Swank, 2006). On the other hand, Snow (1995) argued that appropriately simplified structure and conceptual complexity of CDS is not sufficient in facilitating child linguistic development, if object references are frequently used to redirect the child's focus of attention as opposed to following it. A frequent use of prescriptives or object references that redirect the child's focus of attention has indeed been reported to be related to slower early vocabulary growth and a less varied vocabulary (e.g. Akhtar, Dunham \& Dunham, 1991; Della Corte, Benedict \& Klein, 1983; Masur et al., 2005; Tomasello \& Farrar, 1986). In turn, joint attention refers to a situation in which both the adult and the child are jointly attending to a common aspect of the situation. Joint attention shared by the adult and child helps the child identify the intended target of the adult's utterance, while talking about objects or events in the 'here-and-now' as well as using familiar words for the target information provide further help for the child to understand adult utterances (for a review see Clark, 2009: 36-38).

When considering maternal skills in sharing and maintaining joint attention with a child, the concept of responsiveness is usually brought up. Maternal responsiveness refers to a mother's ability to perceive her child's signals accurately and respond to them promptly, contingently, and appropriately (Bornstein et al., 1999). It has often been shown to be associated with child language outcomes (Bornstein et al., 1999; 
Girolametto et al., 1999, 2002; Hoff \& Naigles, 2002; Kaiser \& Hancock, 2003; Masur et al., 2005; Roberts \& Kaiser, 2011). In turn, constantly redirecting the child's focus of attention and also attempts to command and control the child's behaviour have been considered characteristics of directive interactive style (Della Corte et al., 1983; Hoff \& Naigles, 2002; Masur et al., 2005). However, Pine (1992) has pointed out that behavioural directives are quite frequently used to support an ongoing activity and therefore they do not necessarily have the intrusive quality of attention-directing utterance. Flynn and Masur (2007) have added that possible negative outcomes of directiveness may come about specifically because directive utterances are commonly used to redirect children's attention. Hence, directive utterances may not only be intrusive but also supportive, depending on the child's current focus of attention (see also Akhtar et al., 1991; Lloyd \& Masur, 2014; Masur, Flynn \& Lloyd, 2013; Pine, 1992). For example, Masur et al. (2005) found in their study of mothers and children between the ages $0 ; 10$ and 1;9 that maternal supportive directives were positively and intrusive directives negatively related to children's early advances in expressive vocabulary. All in all, it is important to take into consideration not only the pragmatic but also the attentional aspects of directives.

Bidirectional nature of the relationship between maternal verbal interactive style and child language skills

It is also important to take into consideration that individual characteristics of children in mother-child conversational interactions may influence maternal behaviour (e.g. D’Odorico, Salerni, Cassibba \& Jacob, 1999; Lloyd \& Masur, 2014; Masur et al., 2013). Hence, one might also think that individual variation among children in 
communicative and language abilities at a given age might at least in part explain the differences in verbal interactive style among mothers. This is an important point, because during the early stages of linguistic development quite a considerable level of individual variation and instability can still be considered normal (Clark, 2009: 14; Darrah, Hodge, Magill-Evans \& Kembhavi, 2003; Fenson et al., 1994, 2000; StoelGammon, 2011). Furthermore, characteristics of maternal verbal interactive style that facilitate growth at one age might be irrelevant at another (Masur et al., 2005; Rowe, 2012; Soderstrom, 2007).

Several researchers have suggested that CDS may be more influential around the onset of word production than at later stages of language development (e.g. Barrett, Harris \& Chasin, 1991; D’Odorico et al., 1999; Silvén, Niemi \& Voeten, 2002). It is possible that the role of CDS at least in vocabulary development declines quite sharply once the child has grasped the idea of using words as a vehicle of communication. Hoff and Naigles (2002) added that by the time children have become competent at staying engaged and following their mothers' focus, individual differences in maternal contingency decrease in importance. However, in a study by Dunham, Dunham and Curwin (1993), joint attention parameters were manipulated in order to determine their effects on the ability of children to learn new words at the age of $1 ; 6$. Significant learning advantage for the attention-following versus attention-redirecting context was still found at that age. Hence, in order to make more profound conclusions concerning these matters, further investigations are in order and even up until the third year of children's life. In addition, because according to some earlier findings the way an individual mother talks to her child is significantly determined by the child's own linguistic and communicative ability (see Gleitman, Newport \& Gleitman, 1984; Hampson \& Nelson, 1993; Lloyd \& Masur, 2014; Masur, 1982; Snow, 1995), it would 
be interesting to study to what extent maternal contingency is stable over the course of time during significant changes in children's linguistic skills. However, in a study by Flynn and Masur (2007), maternal responsiveness and intrusive attentional directiveness demonstrated considerable stability between the children's ages of $0 ; 10$ and $1 ; 9$.

\section{The present study}

The purpose of the present longitudinal study was to investigate maternal responsive and directive speech to their children and its role in early linguistic development in a new language community (Finnish). In the analyses of maternal speech, the categories presented earlier by Flynn and Masur (2007) were used. These categories capture aspects of responsive and directive speech that reflect both the essential pragmatic and attentional characteristics. By considering these characteristics simultaneously, it is possible to improve understanding of the critical language-facilitating features of maternal speech. Maternal speech was analysed at age $0 ; 10$, i.e. around the time the children have started to comprehend words and are quite soon expected to produce their own first words. The same analyses were repeated at age 2;0, i.e. around the end of the prelinguistic developmental period (for different stages of prelinguistic development see Mundy \& Gomes, 1997). Although children typically show signs of intentional communication already at the end of their first year and also the word production usually starts soon after that, during the second year of life they still rely quite heavily on nonverbal communicative means. Gradually the usage of gestures and vocalizations in isolation decreases with an increase in the usage of coordinated gestures and vocalizations as well as words (Wetherby, Cain, Yonclas \& Walker, 1988). Finally, towards the end of the second year the usage of communicative acts consisting of only 
words increases. Because the age 2;0 can be considered an important transitional point from prelinguistic to linguistic developmental stage, it could be reflected in maternal interactive style. The role of maternal responsiveness and directiveness may change as children rely heavily on spoken language as their main form of communication. Children's linguistic abilities were assessed at ages 1;0 and 2;6. A number of similar previous studies examined only productive vocabulary as an outcome measure (Akhtar et al., 1991; Bornstein et al., 1999; Masur et al., 2005). In the present study also receptive skills were assessed.

Firstly, we examined the relations between each maternal utterance category separately at the children's age $0 ; 10$ and at 2;0. Secondly, we wanted to know whether there are some changes in the frequencies of maternal responsive and directive utterances over the course of time and to what extent verbal behavioural patterns are stable in individual mothers. To obtain this information, we examined the relations of each utterance category between the children's age points $0 ; 10$ and 2;0. Finally, the relations of maternal utterance categories to child early linguistic development were examined. Our approach in these final analyses was to use the measures of maternal speech from each age to predict the results of the subsequent linguistic assessment.

We used absolute frequencies of maternal utterances in the analyses, because the amount of maternal speech may have a role in promoting child language development (Brent \& Siskind, 2001; Goodman, Dale \& Ping, 2008; Hurtado, Marchman \& Fernald, 2008). However, we also used partial correlational analyses controlling for the total number of utterances, in order to obtain information concerning the characteristics of maternal speech and its role in child language development independently of the overall amount of verbal interaction. Because earlier studies have indicated that during the early stages of development girls tend to produce more words than boys (e.g. Fenson et al., 
1994; Stolt, Haataja, Lapinleimu \& Lehtonen, 2008), the possible effects of gender were also considered, both in terms of child linguistic development and also the measures of maternal speech.

\section{METHOD}

\section{Participants}

Participants were 24 first-born children (12 girls and 12 boys) and their mothers, who were native speakers of Finnish. They were recruited from the maternity ward in a hospital located in northern Finland. All the children were healthy and full term at birth after normal pregnancy and delivery. Families meeting these criteria were selected on the basis of their willingness to participate in a longitudinal study of mother-child interaction and child early linguistic development. All mothers gave their written informed consent to participate.

At the beginning of data collecting, maternal age ranged from 22 to 42 years $(M=$ 27). The mothers were well educated, having completed an average of 17 years of schooling. 15 of them had a tertiary education (e.g. polytechnic, university) and 9 mothers had an upper secondary education (e.g. senior secondary school, vocational and professional education institutions). Households were of middle socioeconomic status based on the occupational status of the parents. 


\section{Procedure}

Participants were visited in their homes by the first author at the children's ages of $0 ; 10$ and 2;0 in order to collect videotaped samples of mother-child interaction. Each dyad was videotaped for about twenty minutes in a semi-structured free-play session using a standard set of age-appropriate toys. The set of toys was adapted from the free-play segment of the Parent-Child Early Relational Assessment (PCERA; Clark, 1985) including e.g. toy telephones, a baby doll, a teddy bear, some building blocks, a ball and a couple of picture books. At 2;0 a shape sorter, crayons and drawing paper as well as a tea set were added. The mothers were instructed to interact with their children in the way they usually did. Videotapes were later transcribed verbatim. The basic unit of the transcription was the utterance. It was defined as any sequence of words or vocalization that is preceded and followed by a pause or a change in conversational turn, topic or intonation pattern. In addition to verbal and vocal utterances the transcripts included nonverbal acts, which served, either alone or in conjunction with a vocalization or speech, to initiate or maintain interaction. Both the maternal and child utterances and nonverbal acts were included in the transcripts. The transcription procedure was carried out by three researchers (second, third, and fourth authors), each of them managing one third of the whole video data. The transcription reliability was checked so that $50 \%$ of the data was re-analysed by another researcher. The percentage of agreement was $100 \%$, concerning the segmentation of the sequences of words and vocalizations into utterances and also the inclusion of nonverbal acts in the transcripts.

With respect to assessment of child linguistic abilities, at the children's age of 1;0 mothers were given a questionnaire: the Finnish version of the MacArthur Communicative Development Inventories (MCDI; Fenson et al., 1994; Lyytinen, 1999). 
At 2;6, the Finnish version of the Reynell Developmental Language Scales III (RDLS III; Edwards et al., 1997; Finnish version, 2001) was administered by the first author during a home visit.

\section{Measures}

Maternal utterances. In this study we employed the categories of mothers' responsive and directive speech that were adapted from the earlier work of Flynn and Masur (2007). These four mutually exclusive categories are: Responsive Utterances, Supportive Directive Utterances, Intrusive Behavioural Directives and Intrusive Attentional Directives. The categorization system takes into consideration both the mother's sensitivity to the child's focus of attention at the time of the utterance and the mother's pragmatic intent. From each videotaped free-play session, altogether ten minutes were analysed with the help of the transcripts, starting from the beginning of the third minute until the end of the twelfth minute.

Utterances that referred to an object, action or attribute on which the child was currently visually focused or with which the child was actively engaged were identified as following the child's attention, whereas others were designated as leading the child's attention (see Akhtar et al., 1991; Landry, Chapienski \& Schmidt, 1986; Masur et al., 2005). Pragmatic categorization reflected the function of the utterance (see Pine, 1992). The definitions of the four categories are as follows:

(a) Responsive Utterances are statements describing a person's behaviour, actions, feelings, etc., or an object or an event present in the immediate situation (e.g. You are patting the dog. The ball is bouncing. Is that a red car?). They are following the child's 
focus of attention. So-called fillers (e.g. uh oh; mm) that were not conveying any referential meaning and appeared to be used as automatic responses were not included. (b) Supportive Directives aim to control the child's physical behaviour by suggesting, commanding or encouraging the child (e.g. Throw the ball to mummy. Let's have a tea party. Could you give me some more tea, please?). They are also following the child's focus of attention.

(c) Intrusive Behavioural Directives have the same pragmatic intent as Supportive Directives, but they direct the child's focus of attention away from the action or object with which the child is currently engaged and/or lead the child's behaviour in a new direction.

(d) Intrusive Attentional Directives attempt to redirect or lead the child's focus of attention (e.g. Look at this picture. Can you see the doll?).

Utterances that were not counted in any of the above-mentioned categories are included in the total number of maternal utterances. In the present study they are not examined further. Nonverbal acts included in the transcripts are not examined either. Still, the inclusion of the nonverbal acts in the transcripts was important for the purposes of the present study, because it made it easier to categorize maternal utterances. Similarly to the transcription, the categorization was also carried out by three researchers. In the beginning of this procedure some parts of the data were viewed together in the whole research group and the principles of categorization were discussed thoroughly. In order to test the reliability of the categorization of maternal utterances, $50 \%$ of the data was re-analysed by another researcher. The percentage of agreement was $91.9 \%$ for the video data collected at the children's age of $0 ; 10$ and $90.2 \%$ for the data collected at the children's age of 2;0 (the number of utterances that were categorized in the same way $\div$ the number of utterances categorized either in the same 
way or differently X $100=$ the agreement \%). Cohen's kappa values were also run to determine the level of agreement between the researchers in categorizing maternal utterances. The values for the video data at $0 ; 10$ and $2 ; 0$ were 0.83 and 0.84 , respectively. For the most part the discrepancy found was between the categories Responsive Utterances and Supportive Directives. Hence, the mother's sensitivity to the child's focus of attention was interpreted in the same way between the researchers, but the mother's pragmatic intent was in some cases unclear. In addition, some utterances that were categorized as responsive by one researcher were not counted in any of the four categories by the other. In these cases the other researcher considered an utterance to be a so-called filler.

Child linguistic measures. For the purposes of assessing early linguistic skills at the children's age of 1;0, the Finnish version of the MacArthur Communicative Development Inventories (MCDI; Fenson et al., 1994; Lyytinen, 1999) was used, which is based on parental reports. The younger children's form of the MCDI, which is designed for children aged $0 ; 8$ to $1 ; 4$, was used in this study. It provides information on children's phrase and vocabulary comprehension as well as vocabulary production. In addition, a composite of early symbolic actions and communicative gestures, a measure called Total Gestures, is derived from parental reports.

The children's linguistic competence at 2;6 was assessed using the Finnish version of the Reynell Developmental Language Scales III (RDLS III; Edwards et al., 1997; Finnish version, 2001). These scales give scores for language comprehension and expressive skills. The Comprehension Scale has 62 items organized into ten sections, which test e.g. comprehension of single words and basic relations between words, understanding of attributes and spatial relations as well as complex grammatical and 
inference skills. The Expressive Scale also has 62 items, in six sections, for which the examiner asks the child e.g. to name objects, describe activities and to define words.

\section{Statistical analyses}

Statistical analyses were produced with the SPSS version 23.0 for Windows.

Descriptive statistics (means, standard deviations and ranges) for maternal utterances are presented first in order to describe the distribution and the amount of variation in the data. The possible effects of gender were assessed using the Student's t-test for independent samples. Thereafter, the relations between the total number of maternal utterances and each utterance category both at the children's age $0 ; 10$ and 2;0 were examined using the Pearson product-moment correlations. Partial correlations controlling for the total number of utterances were used to examine the relations between different utterance categories separately at $0 ; 10$ and 2;0. The Pearson correlations and partial correlations were used to examine the relations between the two age points. In addition, the dependent t-test was used for further investigations of the possible changes in the frequencies of utterances over time.

With regard to the child linguistic measures at $1 ; 0$ and $2 ; 6$, descriptive statistics are presented first. The possible effects of gender were again assessed using the Student's ttest for independent samples. To examine the relations between the different maternal utterance categories and child linguistic measures, the Pearson product-moment correlations and partial correlations controlling for the total number of utterances were used. Our approach was to use the measures of maternal utterances from each age to predict the results of the subsequent linguistic assessment. 


\section{RESULTS}

Maternal responsive and directive speech at the children's ages of 0;10 and 2;0

Descriptive statistics for maternal responsive and directive utterances as well as the total number of utterances at the children's age of $0 ; 10$ are presented in Table 1 and at the children's age of 2;0 in Table 2. As can be seen, individual variation in the frequencies of all the utterance categories as well as in the total amount of maternal speech was considerable. The possible effects of gender were investigated by using Student's t-test for independent samples. No statistically significant gender differences were found.

\section{Insert Tables 1 and 2 about here}

Pearson product-moment correlations were used to analyse the relations between the total number of utterances and the different utterance categories. At the children's age of $0 ; 10$, there were positive correlations between the total number of maternal utterances and the frequencies of Responsive Utterances $(r=0.888, p<0.0001)$, Supportive Directives $(r=0.480, p=0.017)$, and also Intrusive Attentional Directives $(r$ $=0.423, p=0.039)$. The investigations at the age point 2;0 indicated positive correlations between the total number of maternal utterances and the frequencies of Responsive Utterances $(r=0.902, p<0.0001)$ and Intrusive Attentional Directives $(r=$ $0.500, p=0.013)$. Because of these quite consistent associations, the next analyses of maternal verbal interactive style control for utterance frequencies.

Partial correlations controlling for the total number of maternal utterances showed negative relations between responsive and directive utterances at both age points (see 
Table 3). At 0;10 the correlation between Responsive Utterances and Intrusive Behavioural Directives was significant. In addition, there was a negative trend in the correlation between Responsive Utterances and Supportive Directives. At 2;0, Responsive Utterances correlated negatively with Supportive Directives and also with Intrusive Attentional Directives. Furthermore, at 2;0 a positive trend was found between Intrusive Behavioural and Intrusive Attentional Directives.

\section{Insert Table 3 about here}

Changes of maternal responsive and directive utterances with the child's age

The relations in the frequencies of responsive and directive utterances between the two age points were analysed firstly by using Pearson product-moment correlations and secondly by using partial correlations, controlling again for total utterance frequencies at both age points. The results of these analyses are presented in Table 4 .

\section{Insert Table 4 about here}

Pearson correlations showed a positive relationship between Responsive Utterances at the two age points, whereas partial correlation was not statistically significant. Furthermore, Pearson correlations showed a significant positive correlation between Supportive Directives at the children's ages of $0 ; 10$ and 2;0. This relation remained significant when the total utterance frequencies were controlled. In addition, there was a positive correlation between the total number of utterances at the age points $0 ; 10$ and $2 ; 0(r=0.519, p=0.009)$. 
We also used dependent t-test for investigations of the possible changes in the frequencies of different kinds of utterances between the two time points. These analyses indicated that the mothers produced significantly more Responsive Utterances at the children's age of $2 ; 0$ compared to age $0 ; 10$ [ $(p<0.0001,95 \%$ CI $-16.944-(-4.397)]$. By contrast, there were no statistically significant changes in the frequencies of directive utterances. The total utterance frequency increased significantly over time $[p=0.004$, $95 \%$ CI $-46.185-(-10.148)]$.

Relations of maternal responsive and directive utterances to child language outcomes

The descriptive statistics of the language measures are presented in Table 5. One gender difference was found in the measures: Student's t-test for independent samples showed that girls produced more words than boys at 1;0 ( $p=0.049$, CI 95\% 0.019-11.981).

\section{Insert Table 5 about here}

The possible relations between maternal verbal style and children's language outcomes at ages $1 ; 0$ and 2;6 were investigated by using Pearson product-moment correlations and partial correlations. Maternal Responsive Utterances at 0;10 were positively related to a child's ability to comprehend phrases and words at $1 ; 0$, although only the latter was also shown by partial correlation (see Table 6). Rather similar findings were made with regard to Supportive Directives, but these relations were not indicated when the total number of maternal utterances was controlled. In turn, a negative relation between Intrusive Behavioural Directives and Vocabulary Comprehension was found, although only the partial correlation was statistically significant. Furthermore, Pearson 
correlations showed that both maternal Responsive Utterances and Supportive

Directives were positively related to a child's production of early symbolic actions and communicative gestures (Total Gestures). By contrast, none of the maternal utterance category was related to the measure of child Vocabulary Production, as can been seen in Table 6 .

With regard to the total number of utterances, it was positively related to Phrases Understood $(r=0.417, p=0.043)$, Vocabulary Comprehension $(r=0.421, p=0.041)$ and Total Gestures $(r=0.487, p=0.016)$. Instead, the total utterance frequency was not related to Vocabulary Production $(r=-0.032, p=0.882)$.

\section{Insert Table 6 about here}

The investigations of the age points $2 ; 0$ and 2;6 indicated no relations between any maternal utterance category and child language skills (see Table 7). The same was true for the total number of maternal utterances and child comprehensive skills $(r=0.091, p$ $=0.627)$ and also productive skills $(r=-0.034, p=0.875)$.

\section{Insert Table 7 about here}

\section{DISCUSSION}

The purpose of the present longitudinal study was to investigate maternal responsive and directive speech to their children and its role in early linguistic development by applying an analysis procedure presented by Flynn and Masur (2007). In this procedure, maternal verbal utterances are divided into four mutually exclusive categories that are: 
Responsive Utterances, Supportive Directive Utterances, Intrusive Behavioural Directives and Intrusive Attentional Directives. Both the mother's sensitivity to the child's focus of attention at the time of the utterance and the mother's pragmatic intent are taken into consideration. Maternal speech was analysed at the children's ages of $0 ; 10$ and $2 ; 0$. Firstly, the relations between each maternal utterance category both at the children's age 0;10 and at 2;0 were examined. Secondly, the relations of each utterance category between the children's age points $0 ; 10$ and 2;0 were examined. In addition, children's linguistic abilities were assessed at ages $1 ; 0$ and 2;6. Thereafter, the measures of maternal speech from each age were used to predict the results of the subsequent linguistic assessment.

At first it is important to point out that individual differences between mothers in the frequencies of different utterance categories and in the total number of utterances were considerable at both age points. Also Hurtado and others (2008) reported considerable variation between mothers in the amount of speech and also in its variability and complexity. In addition, Rowe (2008) found a relationship between directiveness and a smaller number of words, which is also in accordance with the present findings. In the present study a positive correlation was found between responsive utterances and the total number of utterances at both age points and also between supportive directives and the total number of utterances at the children's age of $0 ; 10$. However, conversely to the findings of Rowe (2008), in the present study a positive correlation was also identified between maternal intrusive attentional directives and the amount of speech at both age points. An interesting question is to what extent the amount of speech and also other features of CDS are individual characteristics of the mother, and to what extent the child contributions in communicative interchanges influence the mother. It could be argued that the way an individual mother talks to her 
child is significantly determined by the child's own linguistic and communicative ability (see Gleitman et al., 1984; Hampson \& Nelson, 1993; Lloyd \& Masur, 2014; Masur, 1982; Snow, 1995). For example, in cases with passive, incomprehensive and inattentive children still in toddlerhood, maternal intrusive directiveness may be an inevitable compensation. In a study of mothers and their children at age 1;3, Lloyd and Masur (2014) found that differential patterns of maternal responsive versus directive behaviours were prompted by different child initiatives (see also Masur et al., 2013). In a study by Vigil, Hodges and Klee (2005), mothers of late-talking toddlers were less responsive and less keen on following the child's focus of attention compared to mothers of typically-developing children (see also van Balkom, Verhoeven \& van Weerdenburg, 2010).

In the examinations of each age point separately, we found some relations between the different maternal utterance categories. Negative correlations between responsive utterances and all the three different kinds of directive utterances were found. These results are partly similar to the findings of Flynn and Masur (2007). They analysed maternal speech at the children's ages of $0 ; 10,1 ; 1,1 ; 5$, and $1 ; 9$. Unlike we had expected, there was a negative correlation between responsive utterances and supportive directives. Similarly to Flynn and Masur, we observed no relations between supportive and intrusive directives. Contrary to the findings of Flynn and Masur, in the present study no relation was found between intrusive behavioural and attentional directives.

When considering the two different age points of the present study, the frequencies of maternal utterance categories were less stable than in the data presented by Flynn and Masur (2007). The last part of the second year in children's life might be a period of such dramatic developmental changes that the maternal interactive style also changes considerably. In the present study, the number of maternal responsive utterances 
increased over time. Flynn and Masur (2007) also found that overall frequencies of responsive utterances as well as supportive directives increased slightly over time. Smolak (1987) reported that the use of directives decreases as children grow older. It is possible that this occurs in conjunction with the increase in the word production of the child and overall with the development of a child's capacities to participate in communicative interactions. Words are likely to be easily perceived as communicative by the adult and hence responded to.

In accordance with several earlier research findings (e.g. Akhtar et al., 1991; Della Corte et al., 1983; Masur et al., 2005; Tomasello \& Farrar, 1986), this study highlights the importance of joint attention shared by the adult and child during the first steps of language acquisition. Maternal responsive utterances and supportive behavioural directives at around the onset of child word production, i.e. at $0 ; 10$, were related to child receptive language skills as well as to the skills in symbolic actions and communicative gestures at the age of 1;0. Quite interestingly, at the same time there was a negative correlation between responsive utterances and supportive directives, as mentioned earlier. Furthermore, both of these categories correlated positively with the total number of maternal utterances. This suggests that not only responsive but also directive interactive style may facilitate child language growth, provided that the directives follow the child's current focus of attention. The results also indicated a negative relationship between maternal intrusive behavioural directives and child receptive vocabulary at $1 ; 0$. In turn, the roles of responsiveness and directiveness appear to decrease in importance by the end of the prelinguistic developmental period, i.e. the time when children are expected to begin to rely on spoken words as their main form of communication. No statistically significant correlations were found between the maternal utterance categories at the children's age of $2 ; 0$ and child language measures at 
2;6. Masur et al. (2005) investigated the role of maternal responsiveness and directiveness to child vocabulary between the children's ages of $0 ; 10$ and $1 ; 9$. They found that maternal responsiveness and also supportive directiveness at the child's age of $1 ; 5$ were positively related to child vocabulary still at $1 ; 9$. The age $2 ; 0$ can be considered an important transitional point from prelinguistic to linguistic developmental stage that could be reflected in maternal interactive style. Furthermore, Hoff and Naigles (2002) have pointed out that once children have reached the first stages of language utilization, semantic contingency of adult utterances to the child's previous utterances or focus of attention may no longer explain the differences among children in their capacities. However, this is not to say that by the end of the second year of children's life CDS loses its facilitating effects altogether. Based on the current literature it is suggested that it is more probable that some other characteristics of CDS become important in explaining later advances in child language development. These characteristics might include lexical diversity (Hoff \& Naigles, 2002; Huttenlocker, Waterfall, Vasilyeva, Vevea \& Hedges, 2010; Rowe, 2008, 2012) as well as syntactical diversity (Hoff \& Naigles, 2002; Huttenlocker et al., 2010), vocabulary sophistication and also the use of different kinds of decontextualized utterances falling into categories such as explanations, pretend, and narrative (Rowe, 2012). Altogether it is likely that certain aspects of parenting affect certain child outcomes and that different aspects are important at different stages of development (Masur et al., 2005; Rowe, 2012; Soderstrom, 2007; Tamis-LeMonda et al., 2001).

To conclude, it is possible that merely revealing the relationship between CDS and child language development does not in itself demonstrate that certain characteristics of CDS actually facilitate children's language acquisition. In a relatively recent research report Song, Spier and Tamis-LeMonda (2014) suggested a bidirectionality in mother- 
child associations. They found that although the quantity and quality of CDS had implications for children, early cognitive skills of children subsequently affected maternal language. However, we should not ignore the presence of individual variation in maternal speech that exists, even when the children are of the same age or linguistic level (e.g. Bornstein et al., 1999; Rescorla \& Fechnay, 1996).

Our observations may not be applicable to other situations or populations, and they should be interpreted with caution because of the small sample size. Altogether, language acquisition is a complex process, and in the present study only a limited set of factors that potentially affect child language development were examined. It is also important to acknowledge that the presence of the researcher and the fact that the mothers and children were videotaped may have affected maternal interactive style at least to some extent. The samples that were analysed were also relatively short, only 10 minutes. However, they were regarded as sufficient, because the length of the samples analysed in the study by Flynn and Masur (2007) was only eight minutes. With regard to the coding scheme, it can be regarded as suitable for the present data. However, it is important to point out that quite a number of maternal utterances were not included in any of the categories. Most of these utterances were so-called fillers that were not conveying any referential meaning and appeared to be used as automatic responses. They were included in the transcripts because they had an important role in maintaining interaction and conversation-like turn-taking structure between the mother and the child. In the present data all of the mothers were relatively similar in their interactive style in the sense that there were altogether a rather small number of intrusive directives. The most considerable variation among the mothers was found actually in the total number of utterances. If there had been more variation in directiveness, it would have been possible to draw more profound conclusions concerning maternal verbal interactive 
style - its consistency, stability and role in child early linguistic development.

Nevertheless, even if the sample of mothers was rather homogeneous as they all were middle class and well educated, some significant relations were found. A Bonferroni correction was not carried out, because the sample size is small and therefore there is the potential to mask true significant findings.

Also with regard to the linguistic measures, a number of limitations should be acknowledged. Firstly, the measures used, the MCDI and RDLS III, were quite different from each other. A relatively limited set of tests and assessment methods are available in Finnish. Secondly, the longitudinal span was limited when examining the role of maternal speech to very early linguistic development. However, we wanted to capture the time around the onset of word production. When examining later development, the longitudinal span was perhaps more appropriate. At 2;6 children are already expected to have many skills that are tested also in the RDLS III, and also more individual variation is likely to be seen than during a little bit earlier developmental stages. Still, it is possible that the RDLS III did not distinguish the children sufficiently.

Regardless of the above-mentioned constraints, the present study provided valuable information on some central characteristics of maternal verbal interactive style, responsiveness and directiveness, during interaction with children at ages $0 ; 10$ and 2;0, as well as concerning the ways in which maternal communicative style can make a relevant contribution to the development of child early linguistic skills. Our findings provide support and also greater specificity to previous findings. Contrary to some earlier studies that examined only productive vocabulary as an outcome measure (Akhtar et al., 1991; Bornstein et al., 1999; Masur et al., 2005), in the present study also receptive skills were assessed. Furthermore, the present study was carried out in a new language community (Finnish). 
All in all, this kind of information can be beneficial when planning early intervention programmes for children with late language emergence, in particular those based on training parents to use language-facilitating communicative strategies. Further studies should in particular aim to capture the transactions between the mothers and their children. In addition, in order to be able to draw conclusions concerning the role of mother-child interaction for children's communicative linguistic development with increased confidence, larger and more diverse samples are needed than that used in the present study. 


\section{REFERENCES}

Akhtar, N., Dunham, F. \& Dunham, P. (1991). Directive interactions and early vocabulary development: the role of joint attentional focus. Journal of Child Language 18, 41-49.

Arshavsky, Y. (2009). Two functions of early language experience. Brain Research Reviews 60, 327-340.

Barrett, M., Harris, M. \& Chasin, J. (1991). Early lexical development and maternal speech: a comparison of children's initial and subsequent uses of words. Journal of Child Language 18, 21-40.

Bornstein, M. H., Tamis-LeMonda, C. S. \& Haynes, O. M. (1999). First words in the second year: continuity, stability, and models of concurrent and predictive correspondence in vocabulary and verbal responsiveness across age and context. Infant Behavior and Development 22, 65-85.

Brent, M. R. \& Siskind, J. M. (2001). The role of exposure to isolated words in early vocabulary development. Cognition 81, B33-B44.

Bruner, J. S. (1981). The social context of language acquisition. Language and Communication 1, 155-178.

Bruner, J. S. (1983). Child's talk: learning to use language. New York: Norton.

Ciccone, N., Hennessey, N. \& Stokes, S. F. (2012). Community-based early intervention for language delay: a preliminary investigation. International Journal of Language \& Communication Disorders 47, 467-470.

Clark, E. (2009). First language acquisition ( $2^{\text {nd }}$ edition). Cambridge, UK: Cambridge University Press. 
Clark, R. (1985). The Parent-Child Early Relational Assessment. Madison, WI:

University of Wisconsin Medical School, Department of Psychiatry.

Darrah, J., Hodge, M., Magill-Evans, J. \& Kembhavi, G. (2003). Stability of serial assessments of motor and communication abilities in typically developing infants implications for screening. Early Human Development 72, 97-110.

Della Corte, M., Benedict, H. \& Klein, D. (1983). The relationship of pragmatic dimensions of mothers' speech to the referential-expressive distinction. Journal of Child Language 10, 34-43.

Desmarais, C., Sylvestre, A., Meyer, F., Bairati, I. \& Rouleau, N. (2008). Systematic review of the literature on characteristics of late-talking toddlers. International Journal of Language \& Communicative Disorders 43, 361-389.

D’Odorico, L., Salerni, N., Cassibba, R. \& Jacob, V. (1999) Stability and change of maternal speech to Italian infants from 7 to 21 months of age: a longitudinal study of its influence on early stages of language acquisition. First Language 19, 313346.

Dunham, P. J., Dunham, F. \& Curwin, A. (1993). Joint-attentional states and lexical acquisition at 18 months. Developmental Psychology 29, 827-831.

Edwards, S., Fletcher, P., Garman, M., Hughes, A., Letts, C. \& Sinka, I. (1997). Reynell Developmental Language Scales III. The University of Reading edition. Berkshire, UK: NferNelson (Translation and standardization of the Finnish version: Psykologien Kustannus Oy, 2001).

Fenson, L., Dale, P. S., Reznick, J. S., Bates, E., Thal, D. \& Pethick, S. J. (1994). Variability in early communicative development. Monographs of the Society for Research in Child Development 59(5, Serial No. 242). 
Fenson, L., Bates, E., Dale, P., Goodman, J., Reznick, S. \& Thal, D. (2000). Measuring variability in early child language: don't shoot the messenger. Child Development $71,323-328$.

Ferguson, C. A. (1978/2004). Talking to children: a search for universals. Reprinted in B. C. Lust \& C. Foley (eds.), First language acquisition: the essential readings. Oxford: Blackwell. (Original work published 1978)

Flynn, V. \& Masur, E. (2007). Characteristics of maternal verbal style: responsiveness and directiveness in two natural contexts. Journal of Child Language 34, 519-543.

Furrow, D., Nelson, K. \& Benedict, H. (1979). Mothers' speech to children and syntactic development: some simple relationships. Journal of Child Language $\mathbf{6}$, $423-442$.

Gibbard, D., Coglan, L. \& MacDonald, J. (2004). Cost-effectiveness analysis of current practice and parent intervention for children under 3 years presenting with expressive language delay. International Journal of Language \& Communication Disorders 39, 229-244.

Girolametto, L., Bonifacio, S., Visini, C., Weitzman, E., Zocconi, E. \& Pearce, P. S. (2002). Mother-child interactions in Canada and Italy: linguistic responsiveness to late-talking toddlers. International Journal of Communication Disorders 37, $153-$ 171.

Girolametto, L., Weitzman, E., Wiigs, M. \& Pearce, P. (1999). The relationship between maternal language measures and language development in toddlers with expressive vocabulary delays. American Journal of Speech-Language Pathology 8 , $364-74$.

Gleitman, L., Newport, E. \& Gleitman, H. (1984). The current status of the motherese hypothesis. Journal of Child Language 11, 43-79. 
Goodman, J. C., Dale, P. S. \& Ping, L. (2008) Does frequency count? Parental input and the acquisition of vocabulary. Journal of Child Language 35, 515-531.

Hampson, J. \& Nelson, K. (1993). The relation of maternal language to variation in rate and style of language acquisition. Journal of Child Language 20, 313-342.

Harrison, L. J. \& McLeod, S. (2010). Risk and protective factors associated with speech and language impairment in a nationally representative sample of 4- to 5-year-old children. Journal of Speech, Language, and Hearing Research 53, 508-529.

Hoff, E. \& Naigles, L. (2002). How children use input to acquire a lexicon. Child Development 73, 418-433.

Hurtado, N., Marchman, V. A. \& Fernald, A. (2008). Does input influence uptake? Links between maternal talk, processing speed and vocabulary size in Spanishlearning children. Developmental Science 11, 31-39.

Huttenlocher, J., Waterfall, H. R., Vasilyeva, M., Vevea, J. L. \& Hedges, L. V. (2010). Sources of variability in children's language growth. Cognitive Psychology 61, $343-365$.

Kaiser, A. P. \& Hancock, T. B. (2003). Teaching parents new skills to support their young children's development. Infants \& Young Children 16, 9-21.

Landry, S. H., Chapienski, M. L. \& Schmidt, M. (1986). Effects of maternal attentiondirecting strategies on preterms' response to toys. Infant Behavior and Development 9, 257-269.

Landry, S. H, Smith, K. E. \& Swank, P. R. (2006). Responsive parenting: establishing early foundations for social, communication, and independent problem-solving skills. Developmental Psychology 42, 627-642.

Lloyd, C. A. \& Masur, E. F. (2014). Infant behaviors influence mothers' provision of responsive and directive behaviors. Infant Behavior \& Development 37, 276-285. 
Lyytinen, P. (1999) MCDI-testi: varhaisen kommunikaation ja kielen kehityksen arviointimenetelmä [MCDI test: an assessment method for early communicative and language development]. Jyväskylä, Finland: University of Jyväskylä and the Niilo Mäki Institute.

Masur, E. F. (1982). Mothers' responses to infants' object-related gestures: influences on lexical development. Journal of Child Language 9, 23-30.

Masur, E. F., Flynn, V. \& Eichorst, D. L. (2005). Maternal responsive and directive behaviours and utterances as predictors of children's lexical development. Journal of Child Language 23, 63-91.

Masur, E. F., Flynn, V. \& Lloyd, C. A. (2013). Infants' behaviors as antecedents and consequents of mothers' responsive and directive utterances. First Language 33, $354-371$.

Mundy, P. \& Gomes, A. (1997). A skills approach to early language development: lessons from research on developmental disabilities. In L. B. Adamson \& M. A. Romski (eds.), Communication and language acquisition. Discoveries from atypical development. Baltimore: Paul $\mathrm{H}$. Brookes.

Pine, J. (1992). Maternal style at the early one-word stage: re-evaluating the stereotype of the directive mother. First Language 12, 169-186.

Rescorla, L. \& Fechnay, T. (1996). Mother-child synchrony and communicative reciprocity in late-talking toddlers. Journal of Speech and Hearing Research 39, 200-208.

Roberts, M. Y. \& Kaiser, A. P. (2011). The effectiveness of parent-implemented language interventions: a meta-analysis. American Journal of Speech-Language Pathology 20, 180-199. 
Rowe, M. L. (2008). Child-directed speech: relation to socioeconomic status, knowledge of child development and child vocabulary skill. Journal of Child Language 35, 185-205.

Rowe, M. L. (2012). A longitudinal investigation of the role of quantity and quality of child-directed speech in vocabulary development. Child Development 83, 17621774.

Silvén, M., Niemi, P. \& Voeten, M. J. M. (2002). Do maternal interaction and early language predict phonological awareness in 3- to 4-year-olds? Cognitive Development 17, 1133-1155.

Smolak, L. (1987). Child characteristics and maternal speech. Journal of Child Language 14, 481-492.

Snow, C. E. (1995). Issues in the study of input: finetuning, universality, individual and developmental differences, and necessary causes. In P. Fletcher \& B. MacWhinney (eds.), The handbook of child language. Oxford, UK: Blackwell.

Song, L., Spier, E. T. \& Tamis-LeMonda, C. S. (2014). Reciprocal influences between maternal language and children's language and cognitive development in lowincome families. Journal of Child Language 41, 305-326.

Soderstrom, M. (2007). Beyond babytalk: re-evaluating the nature and content of speech input to preverbal infants. Developmental Review 27, 501-532.

Stoel-Gammon, C. (2011). Relationships between lexical and phonological development in young children. Journal of Child Language 38, 1-34.

Stolt, S., Haataja, L., Lapinleimu, H. \& Lehtonen, L. (2008). Early lexical development of Finnish children - a longitudinal study. First Language 28, 259-279. 
Tamis-LeMonda, C. S., Bornstein, M. H. \& Baumwell, L. (2001). Maternal responsiveness and children's achievement of language milestones. Child Development 72, 748-767.

Tomasello, M. (2003). Constructing a language: a usage-based theory of language acquisition. Cambridge, MA: Harvard University Press.

Tomasello, M. \& Farrar, J. (1986). Joint attention and early language. Child Development 57, 1454-1463.

van Balkom, H., Verhoeven, L. \& van Weerdenburg, M. (2010). Conversational behaviour of children with developmental language delay and their caretakers. International Journal of Language \& Communication Disorders 45, 295-319.

Vigil, D. C., Hodges, J. \& Klee, T. (2005). Quantity and quality of parental language input to late-talking toddlers during play. Child Language Teaching and Therapy $21,107-122$.

Vygotsky, L. S. (1978). Mind in society: the development of higher psychological processes. Cambridge, MA: Harvard University Press.

Wetherby, A. M., Cain, D. H., Yonclas, D. G. \& Walker, V. G. (1988). Analysis of intentional communication of normal children from the prelinguistic to the multiword stage. Journal of Speech and Hearing Research 31, 240-252. 
TABLE 1. Mean frequencies, standard deviations and ranges of maternal utterances at the children's age of $0 ; 10$

\begin{tabular}{lccc}
\hline Utterance category & Mean & SD & Range \\
\hline Responsive Utterances & 70.58 & 27.34 & $31-130$ \\
Supportive Directives & 18.13 & 7.91 & $2-31$ \\
Intrusive Behavioural Directives & 2.25 & 2.31 & $0-7$ \\
Intrusive Attentional Directives & 5.75 & 5.48 & $0-17$ \\
Total number of utterances & 116.21 & 39.25 & $58-171$ \\
\hline
\end{tabular}


TABLE 2. Mean frequencies, standard deviations and ranges of maternal utterances at the children's age of $2 ; 0$

\begin{tabular}{lccc}
\hline Utterance category & Mean & SD & Range \\
\hline Responsive Utterances & 102.58 & 38.88 & $36-171$ \\
Supportive Directives & 19.58 & 11.39 & $3-50$ \\
Intrusive Behavioural Directives & 1.54 & 2.83 & $0-12$ \\
Intrusive Attentional directives & 3.88 & 4.40 & $0-18$ \\
Total number of utterances & 144.38 & 46.72 & $57-244$ \\
\hline
\end{tabular}


TABLE 3. Partial correlations between maternal responsive and directive utterance frequencies at the children's ages of $0 ; 10$ and 2;0, controlling for the total number of utterances. P-values are in parentheses.

\section{Ages}

Utterance category $\quad 0 ; 10 \quad 2 ; 0$

Responsive Utterances and

Supportive Directives

Intrusive Behavioural Directives

Intrusive Attentional Directives

Supportive Directives and

Intrusive Behavioural Directives

$0.179(0.415)$

$-0.352(0.100)$

Intrusive Attentional Directives

Intrusive Behavioural Directives and
$-0.398(0.060)$

$-0.819(<0.0001)$

$-0.509(0.013)$

$-0.354(0.098)$

$-0.358(0.094)$

$-0.437(0.037)$ 
TABLE 4. Pearson product-moment correlations and partial correlations, controlling for total utterance frequencies, between the measures of maternal responsive and directive utterances at the children's ages of $0 ; 10$ and 2;0. P-values are in parentheses.

\begin{tabular}{lcc}
\hline Utterance category & Pearson & Partial \\
\hline Responsive Utterances & $0.465(0.022)$ & $0.168(0.456)$ \\
Supportive Directives & $0.527(0.008)$ & $0.460(0.031)$ \\
Intrusive Behavioural Directives & $0.012(0.957)$ & $0.036(0.873)$ \\
Intrusive Attentional Directives & $0.378(0.069)$ & $0.261(0.240)$ \\
\hline
\end{tabular}


TABLE 5. Means, standard deviations and ranges for the child language measures at 1;0 and $2 ; 6$

\begin{tabular}{lccc}
\hline Measure & Mean & SD & Range \\
\hline MCDI $^{\mathrm{a}}$ & & & \\
Phrases Understood & 14.50 & 6.35 & $2-23$ \\
Vocabulary Comprehension & 100.21 & 63.57 & $11-227$ \\
Vocabulary Production & 9.42 & 7.56 & $1-23$ \\
Total Gestures & 30.00 & 8.93 & $16-47$ \\
& & & \\
RDLS III & & & \\
Comprehension Scale & & 6.33 & $27-48$ \\
Expressive Scale & 38.00 & 5.29 & $8-28$ \\
\hline The MacArthur Communicative Development Inventories. & \\
Developmental Language Scales III. &
\end{tabular}


TABLE 6. Pearson product-moment correlations and partial correlations, controlling for total utterance frequencies, between the maternal responsive and directive utterances at the children's age 0;10 and child language measures at 1;0. P-values are in parentheses.

\begin{tabular}{|c|c|c|c|c|}
\hline \multirow[b]{2}{*}{ Utterance category } & \multicolumn{4}{|c|}{ MCDI } \\
\hline & Phrases Understood & Vocabulary & Vocabulary Production & Total Gestures \\
\hline & & Comprehension & & \\
\hline \multirow[t]{2}{*}{ Responsive Utterances } & $0.495(0.014)$ & $0.591(0.002)$ & $0.015(0.945)$ & $0.495(0.014)$ \\
\hline & $0.299(0.165)$ & $0.521(0.011)$ & $0.094(0.668)$ & $0.156(0.476)$ \\
\hline \multirow[t]{2}{*}{ Supportive Directives } & $0.447(0.029)$ & $0.393(0.058)$ & $0.137(0.522)$ & $0.464(0.023)$ \\
\hline & $0.310(0.151)$ & $0.239(0.271)$ & $0.174(0.427)$ & $0.300(0.165)$ \\
\hline \multirow[t]{2}{*}{ Intrusive Behavioural Directives } & $-0.205(0.337)$ & $-0.361(0.060)$ & $-0.315(0.133)$ & $-0.078(0.717)$ \\
\hline & $-0.316(0.142)$ & $-0.525(0.010)$ & $-0.315(0.143)$ & $-0.197(0.368)$ \\
\hline \multirow[t]{2}{*}{ Intrusive Attentional Directives } & $0.061(0.776)$ & $-0.008(0.971)$ & $0.224(0.292)$ & $0.359(0.085)$ \\
\hline & $-0.140(0.525)$ & $-0.226(0.300)$ & $0.262(0.226)$ & $0.193(0.377)$ \\
\hline
\end{tabular}


TABLE 7. Pearson product-moment correlations and partial correlations, controlling for total utterance frequencies, between the maternal responsive and directive utterances at the children's age 2;0 and child language measures at 2;6. P-values are in parentheses.

\begin{tabular}{lll}
\hline & \multicolumn{2}{c}{ RDLS III } \\
\cline { 2 - 3 } Utterance categories & $-0.072(0.736)$ & $0.209(0.327)$ \\
\hline Responsive Utterances & $-0.097(0.661)$ & $0.034(0.877)$ \\
Supportive Directives & $0.200(0.348)$ & $0.139(0.516)$ \\
Intrusive Behavioural Directives & $0.215(0.325)$ & $0.092(0.675)$ \\
& $-0.036(0.866)$ & $-0.179(0.402)$ \\
Intrusive Attentional Directives & $-0.034(0.879)$ & $-0.203(0.353)$ \\
& $-0.269(0.204)$ & $0.121(0.574)$ \\
& $-0.291(0.178)$ & $0.015(0.945)$ \\
\hline
\end{tabular}

